\title{
Prenatal Estrogen and Progesterone Deprivation Impairs Alveolar Formation and Fluid Clearance in Newborn Piglets
}

\author{
ANDREAS TROTTER, MICHAEL EBSEN, EVANGELOS KIOSSIS, SABINE MEGGLE, EVA KUEPPERS, CORDIAN BEYER, \\ FRANK POHLANDT, LUDWIG MAIER, AND ULRICH H. THOME
}

\begin{abstract}
Division of Neonatology and Pediatric Critical Care Medicine [A.T., F.P., U.H.T.], Pharmacy [L.M.], University of Ulm, 89075 Ulm Germany; Department of Pathology [M.E.], University of Bochum, 44780 Bochum, Germany; Clinic for Veterinary Gynecology and Obstetrics [E.K.], University of Munich, 80539 Munich, Germany; Department of Anatomy and Cell Biology [S.M., E.K.], University of Ulm, 89069 Ulm, Germany; Institute of Neuroanatomy [C.B.], University Hospital, RWTH Aachen, 52074 Aachen, Germany
\end{abstract}

\begin{abstract}
Exposure to high levels of estradiol (E2) and progesterone $(\mathrm{P})$ derived from the fetoplacentomaternal unit during the last trimester of pregnancy may play a crucial role in prenatal lung development and immediate postnatal alveolar fluid clearance (AFC). To measure prenatal alveolar formation and postnatal amiloridesensitive AFC after pharmacological deprivation of E2 and P in utero, fetuses from five sows received an intramuscular depot injection of the E2 receptor blocker ICI 182.780 (ICI) and the P receptor blocker RTI 3021-022 (RTI) and fetuses of five other sows received a placebo injection (control group) during a laparotomy at $90 \mathrm{~d}$ of gestation (term gestation, $115 \mathrm{~d}$ ). Piglets were delivered by cesarean section on d 114 of gestation. Of 95 live-born piglets, 35 were mechanically ventilated. The airways of the right lower lobe were isolated by a balloon catheter wedged in the bronchus and 5\% albumin in $0.9 \% \mathrm{NaCl}$ with or without $1 \mathrm{mmol} / \mathrm{L}$ amiloride was instilled. Amiloride-sensitive AFC was calculated from the protein concentration changes in fluid recovered after $120 \mathrm{~min}$ as the percentage of absorbed fluid. Lungs were removed under standardized conditions to perform alveolar counts. Prenatal treatment with ICI and RTI resulted in a significantly lower amiloride-sensitive AFC (median, 31\%; min-max, -4-58) than placebo (74\%, 18-231). Median alveolar counts per visual field were significantly lower in piglets that were exposed to ICI and RTI $(38,21-78)$ compared with placebo $(56,32-113)$. We conclude that prenatal E2 and P deprivation significantly impaired alveolar formation and amiloride-sensitive AFC. (Pediatr Res 60: 60-64, 2006)
\end{abstract}

$\mathrm{P}$ renatal estrogen supply is essential for the proper development of mammalian organs, such as the reproductive system, skeletal muscle, bone, and brain $(1,2)$. The high prenatal mRNA expression of estrogen and progesterone receptors in the mouse lung (3) suggests that E2 and P may be involved in mammalian fetal lung development.

Vectorial $\mathrm{Na}^{+}$transport of lung epithelial cells drives AFC, which is crucial for postnatal survival. Newborn mice lacking the alpha subunit of the amiloride-sensitive epithelial $\mathrm{Na}^{+}$ channel $(\mathrm{ENaC})$ failed to clear their lung fluid and died of

Received July 29, 2005; accepted March 2, 2006.

Correspondence: Andreas Trotter, M.D., Section of Neonatology, Center for Perinatal Medicine, Children's Hospital, University of Bonn, Sigmund-Freud-Str. 25, 53105 Bonn, Germany; e-mail: andreas.trotter@web.de

DOI: $10.1203 / 01 . p d r .0000220360 .77567 . d 8$ respiratory failure (4). Simultaneous administration of E2 and $\mathrm{P}$ stimulated the expression of $\mathrm{ENaC}$ subunits in rats and increased short circuit current in isolated alveolar type II cells (5). Infants with respiratory distress syndrome appeared to have subnormal epithelial vectorial $\mathrm{Na}^{+}$transport $(6,7)$, which may be aggravated by premature withdrawal of placental E2 and $\mathrm{P}$ supply following premature birth.

Estrogens modulate the dimension of the lung's gasexchange surface area and alveoli in female rats (8). Administration of E2 to pregnant rabbits resulted in thinner alveolar septa and a higher proportion of differentiated alveolar cells (9). Postnatal administration of estrogen to preterm infants reduced the incidence of respiratory distress syndrome (10).

To investigate the effects of simultaneous E2 and P withdrawal in the intrauterine environment, E2 and P actions were pharmacologically blocked by fetal injection of the E2 receptor antagonist ICI and the P receptor antagonist RTI at $90 \mathrm{~d}$ of gestation (term gestation, $115 \mathrm{~d}$ ). Both substances are highly specific with negligible intrinsic activity at the glucocorticoid receptor (11-13). The domestic pig was chosen because its endocrinological (14) and developmental (15) profile during pregnancy is similar to that of humans. We hypothesized that alveolar formation and postnatal amiloride-sensitive AFC in the piglets would be impaired by intrauterine treatment with ICI and RTI. As amiloride-sensitive AFC cannot be measured directly, it was defined as the difference of AFC measurements in the absence or presence of the $\mathrm{ENaC}$ blocker amiloride (16).

\section{SUBJECTS AND METHODS}

All experiments were performed according to current animal care guidelines and approved by the animal research review board of the state government of Bavaria, Germany. Twelve sows of the race Deutsche Landrasse were inseminated with semen from boars of the same race at a local commercial breeding facility. One week before the first procedure, the sows were transferred to the Department of Veterinary Gynecology and Obstetrics (Ludwig-

Abbreviations: AFC, alveolar fluid clearance; BPD, bronchopulmonary dysplasia; E2, $17-\beta$-estradiol $(\mathrm{pg} / \mathrm{mL} \times 3.671=\mathrm{pmol} / \mathrm{L}) ; \mathbf{E N a C}$, epithelial sodium channel; ICI 182.780, $7 \alpha$-[9-[(4,4,5,5,5-pentafluoropentyl)sulfinyl] nonyl]-estra-1,3,5(10)-triene-3,1 7 $\beta$-diol; $\mathbf{P}$, progesterone $(\mathrm{ng} / \mathrm{mL} \times 3.18=$ nmol/L); RTI 3021-022, $11 \beta$-[4-( $N, N$-dimethylamino)phenyl]-16 $\alpha$-ethyl-19norpregna-4,9-dien-3,20-dione 
Maximilians-University, Munich, Germany), where they were kept in farrowing crates and fed a standardized diet three times daily (Deuka Porfina U, Deuka Deutsche Tiernahrung, Regensburg, Germany).

Prenatal treatment of fetuses. Injection of the fetuses was performed on $\mathrm{d}$ 90 of gestation. After a 16-h fast, the pregnant sows were sedated with an intramuscular injection of $2 \mathrm{mg} / \mathrm{kg}$ azaperon (Stresnil, Janssen-Cilag, Neuss, Germany), $10 \mathrm{mg} / \mathrm{kg}$ ketamine (Ursotamin, Serumwerke, Bernburg, Germany), and $0.02 \mathrm{mg} / \mathrm{kg}$ atropine (Braun, Melsungen, Germany). After 10-15 min, intravenous access through an ear vein was established and bolus injections of 2.5-5 mg/kg thiamylal sodium (Surital, Pharmacia \& Upjohn, Erlangen, Germany) were given as needed to maintain sufficient anesthesia. Tocolysis was ensured by $0.3 \mathrm{mg}$ clenbuterol hydrochloride (Planipart, Boehringer, Ingelheim, Germany) administered intramuscularly. The laparotomy site was infiltrated with $80-100 \mathrm{~mL} 2 \%$ procaine hydrochloride (Procasel 2\%, Selectavet; Dr. Otto Fischer, Weyarn-Holzolling, Germany). Both uterine horns were exteriorized through a left-sided laparotomy and the fetuses palpated through the uterine wall. Fetuses of six sows received an intragluteal injection of the E2 receptor blocker ICI ( $2 \mathrm{mg}$; AstraZeneca, Wedel, Germany) and the P receptor blocker RTI (10 mg; kind gift from C. E. Cook, Research Triangle Park, NC), both dissolved in $1 \mathrm{~mL}$ of sesame oil. Arbitrarily, the dose of RTI was five times that of ICI because of the higher $\mathrm{P}$ compared with E2 plasma levels (17). Fetuses of six other sows received a placebo injection with pure sesame oil (control group; Fig. 1). All fetuses from the same sow received the same treatment to avoid exposure of placebo fetuses to ICI or RTI given to littermates. The injection site was marked by subsequent injection of $0.5 \mathrm{~mL}$ guajazulen $6 \%$ in lipiodol (kind gift from P.-E. Heyde, Pharmacy, Eberhard-Karls-University, Tübingen, Germany). Accurate injection was confirmed postmortem by demonstrating blue dye in the gluteal muscles. Antibiotic treatment with $2.5 \mathrm{mg} / \mathrm{kg}$ enrofloxacin (Baytril, Bayer Vital GmbH, Leverkusen, Germany) of the sow was started before the procedure and continued for $5 \mathrm{~d}$. The fetuses were delivered at $114 \mathrm{~d}$ of gestation (term, $115 \mathrm{~d}$ ) by cesarean section under the same anesthetic procedure for the sow.

Postnatal care of the piglets. The piglets (maximum four at a time) were placed on standard neonatal care units with a heated mattress and radiant warmer (Babytherm, Dräger, Lübeck, Germany), maintaining a rectal temperature between 37.5 and $38.5^{\circ} \mathrm{C}$. After anesthesia with $60 \mathrm{mg} / \mathrm{kg}$ thiamylal sodium intramuscularly, a $3.0-\mathrm{mm}$ (inner diameter) uncuffed endotracheal tube was inserted through a tracheotomy and sealed by ligation around the trachea. Mechanical ventilation with a rate of $60 / \mathrm{min}$, inspiratory time $0.3 \mathrm{~s}$, positive end-expiratory pressure $5 \mathrm{mbar}, \mathrm{FiO}_{2} 1.0$ was applied using neonatal ventilators (Leoni, Heinen und Löwenstein, Bad Ems, Germany). Peak inspiratory pressure (PIP) was adjusted as needed to achieve adequate chest rise and an arterial partial pressure of $\mathrm{CO}_{2}\left(\mathrm{PaCO}_{2}\right)$ of $35-45 \mathrm{~mm} \mathrm{Hg}$.

Umbilical arterial and venous lines were placed and perfused with 4 $\mathrm{mL} / \mathrm{kg} / \mathrm{h}$ normal saline (arterial) and $8 \mathrm{~mL} / \mathrm{kg} / \mathrm{h} 5 \%$ glucose electrolyte solution (venous, in mmol/L: $\mathrm{Na}^{+} 35, \mathrm{~K}^{+} 18, \mathrm{Ca}^{2+} 1, \mathrm{Mg}^{2+} 1.5$, acetate 20, $\mathrm{Cl}^{-} 34$, malate 3, phosphate 2, glucose 278). Anesthesia was maintained by continuous infusion of $7 \mathrm{mg} / \mathrm{kg} / \mathrm{h}$ propofol (Disoprivan $2 \%$, AstraZeneca $\mathrm{GmbH}$, Wedel, Germany) and $9 \mu \mathrm{g} / \mathrm{kg} / \mathrm{h}$ fentanyl (Fentanyl-Janssen, JanssenCilag GmbH, Neuss, Germany). Infusion was stopped when all pain reflexes and respiratory drive were abolished and a downward trending blood pressure indicated overly deep anesthesia. If a piglet died early during the above

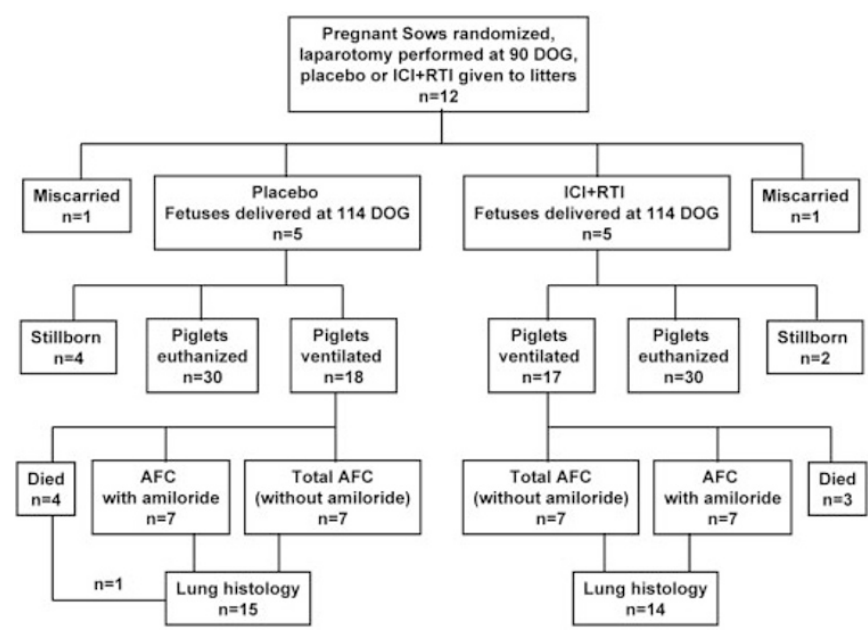

Figure 1. Path of sows and piglets through this study. procedures, another piglet was delivered as needed. The remaining piglets and the sow were euthanized.

Measurement of alveolar fluid clearance. AFC was measured as described (16). In brief, a 4F cardiac wedge catheter (Arrow, Reading, PA) was inserted through a tracheal incision into the right lower lobe bronchus (position confirmed postmortem). The balloon was inflated and tight wedge confirmed by gentle pull. Thereafter, $4 \mathrm{~mL} / \mathrm{kg}$ of $5 \%$ fatty acid free bovine serum albumin (BSA) (A8806, Sigma Chemical Co., St. Louis, MO) dissolved in $0.9 \% \mathrm{NaCl}$ was instilled into the right lower lobe and the catheter cleared by subsequent injection of $0.5 \mathrm{~mL} \mathrm{O}$. For every second piglet, the instilled fluid also contained $1 \mathrm{mmol} / \mathrm{L}$ amiloride (Product 105719, Synopharm, Barsbüttel, Germany). After $2 \mathrm{~h}$, the fluid was recovered in $0.5-\mathrm{mL}$ increments from surviving piglets, and the protein concentration in the last increment most closely resembling alveolar fluid was measured with a standard photometric assay, calibrated with BSA. The AFC as the percentage of absorbed fluid was calculated as follows: $\mathrm{AFC}=\left(1-\mathrm{C}_{\mathrm{i}} / \mathrm{C}_{\mathrm{t}}\right) * 100 / 0.95$, where $C_{i}$ is the initial protein concentration in the instillate $(0.05 \mathrm{~g} / \mathrm{mL}), C_{t}$ is the protein concentration in fluid recovered after $2 \mathrm{~h}$, and 0.95 is the approximate proportion of water in 5\% albumin solution.

Piglets instilled with an albumin solution also containing amiloride yielded measurements of amiloride-insensitive AFC because amiloride-sensitive pathways were blocked. Piglets instilled with amiloride-free albumin solution yielded total AFC. To determine amiloride-sensitive AFC, resembling ENaC activity, subsequent piglets of the same study group instilled with or without amiloride were assigned in pairs, and the difference in AFC between the members of each pair calculated: amiloride-sensitive $\mathrm{AFC}=$ total $\mathrm{AFC}$ (piglet without amiloride) - amiloride-insensitive AFC (piglet with amiloride).

Measurement of lung function. Alveolar partial pressure of oxygen $\left(\mathrm{PaO}_{2}\right)$ was estimated using the alveolar gas equation simplified for $\mathrm{Fio}_{2}=1.0$. The arterial blood gas analysis yielding the highest $\mathrm{PaO}_{2}$ value of each piglet was used for the calculation: $\mathrm{PaO}_{2}=\mathrm{P}_{\text {tot }}-\mathrm{P}_{\text {vap }}-\mathrm{Paco}_{2} / 0.8$, where $\mathrm{P}_{\text {tot }}$ is the atmospheric pressure + mean airway pressure, $\mathrm{P}_{\text {vap }}$ is vapor pressure of water $\left(50 \mathrm{~mm} \mathrm{Hg}\right.$ at $38^{\circ} \mathrm{C}$ ), $\mathrm{PacO}_{2}$ is the arterial $\mathrm{PCO}_{2}$, and 0.8 is the respiratory quotient.

The $\mathrm{AaDO}_{2}$ was defined as $\mathrm{AaDO}_{2}=\mathrm{PAO}_{2}-\mathrm{PaO}_{2}$.

A Stephanie ventilator (Stephan Medizintechnik, Gackenbach, Germany), equipped with a pneumotachograph, was available for measurement of dynamic compliance and resistance using the least squares algorithm. Peak pressure was reduced during the measurement to ensure that the measurement was performed in the steep part of the pressure-volume curve. All lung function measurements were completed before insertion of the bronchial catheter for AFC measurement.

Measurement of ICI plasma levels. Plasma levels of ICI were determined by Analytico Medinet (Breda, The Netherlands) using liquid chromatography and mass spectroscopy, in fetuses aborted $1 \mathrm{wk}$ after intramuscular injection and in fetuses delivered on d 114, i.e. $1 \mathrm{~d}$ before term. Measurement of RTI plasma levels was not available.

Lung histology. Lungs were fixed as described (18). In brief, the ventilator was set to 10 mbar continuous positive airway pressure. The chest was opened, the pulmonary artery cannulated, the left atrium opened, and the lung perfused with Ringer's lactate solution until the liquid draining from the incised left atrium was clear. Thereafter, an aqueous solution of $4.6 \%$ formaldehyde and $0.5 \%$ glutaraldehyde was infused into the pulmonary artery for $10 \mathrm{~min}$, the trachea ligated, and the lung removed and immersed in the same formaldehyde-glutaraldehyde solution. Tissue from four areas in the left lung, i.e. the anterior and posterior parts of the upper and lower lobe, were embedded in paraffin and stained with hematoxylin-eosin and evaluated by a pathologist blinded to the study group assignment. From every area, mean alveolar counts from five visual fields containing alveoli with the greatest diameters and without elements of bronchi were determined at a magnification of $\times 400$ under light microscopy. In every visual field, a line $200 \mu \mathrm{m}$ long was drawn crossing as many alveoli as possible (19). Diameter and septal thickness were measured in all alveoli crossed by the line. Variables scored to document lung injury were alveolar and interstitial inflammation, alveolar and interstitial hemorrhage, edema, atelectasis, and necrosis (20). Each variable was scored using a 0 to 4 -point scale, with no injury scored as 0 , injury in $25 \%$ of the field scored as 1 , injury in $50 \%$ of the field scored as 2, injury in $75 \%$ of the field scored as 3, and injury throughout the field scored as 4 . The maximum possible score was 36

Statistical analysis. The paucity of data regarding effects of ICI and RTI prevented a sample size calculation. We arbitrarily planned 10 sows, five per study group, owing to the high demand of animal care resources and a limited supply of RTI. The sows were assigned to the study groups according to a randomization list provided by a statistician. Student's $t$ test and MannWhitney $U$ test were used to compare the results between the groups. A $p$ value $<0.05$ was considered to be significant. 


\section{RESULTS}

From 12 sows enrolled, two aborted 1 wk after the fetal intramuscular injection (one placebo, one ICI+RTI). In the placebo group and the ICI+RTI group, 48 and 47 piglets, respectively, were delivered alive (four and two piglets stillborn, respectively; Fig. 1). The characteristics of the sows and their litters were not different between the groups (Table 1).

We attempted to perform AFC measurements in 35 piglets. Three piglets died within $1 \mathrm{~h}$ of birth from arterial hypotension and were immediately replaced by littermates. Another four piglets of different litters (two ICI+RTI, two placebo) died of pneumothorax after insertion of the bronchial catheter (probably caused by the catheter penetrating the lung or too much inflation of the balloon rupturing a bronchus), leaving 28 piglets (14 placebo, 14 ICI+RTI) derived from all 10 available litters contributing data to the AFC measurement (Fig. 1).

From each of the two study groups (ICI+RTI and placebo), seven piglets were instilled with amiloride-free albumin solution and seven with amiloride-containing solution, thus subdividing the piglets into four subgroups (Fig. 1). Each subgroup included representatives of all five litters of each study group. Subgroups did not differ in their birth weights.

Total AFC (measured without amiloride) was similar in both study groups. Median and minimum-maximum values were placebo $2.4 \%$, from $-26.8 \%$ to $52.2 \%$; ICI + RTI $7.0 \%$, from $-24.5 \%$ to $31.1 \%$. Values in the presence of amiloride (amiloride-insensitive AFC) were significantly lower $(p<$ $0.05)$ in piglets having received placebo on d 90 of gestation (median, $-37.7 \%$, from $-257.9 \%$ to $-13.8 \%$, compared with those receiving ICI+RTI (median, $-20.1 \%$, from $-30.9 \%$ to $-5.43 \%$. Consequently, the amiloride-sensitive AFC was significantly higher in piglets having received placebo compared with those receiving ICI and RTI $(p<0.05$, Fig. 2$)$. There was no difference between male and female pairs (not shown).

$\mathrm{AaDO}_{2}$ was not different between groups, although there appeared to be a trend toward lower values in piglets receiving ICI+RTI. C and R were similar in both study groups (Table 2).

Alveolar counts were performed on two to four piglets per litter. Maximal and median alveolar counts in the ICI+RTI group were always lower than those in the placebo group in all lung areas studied (Table 3). This difference was most pronounced in the posterior lower lobe $(p<0.05)$. Taking all

Table 1. Characteristics of the sows and piglets

\begin{tabular}{lcc}
\hline \multicolumn{1}{c}{ Sows } & Placebo $(n=5)$ & ICI+RTI $(n=5)$ \\
\hline Weight $(\mathrm{kg})$ at 90 d gestation & $166(147-182)$ & $162(120-200)$ \\
Weight $(\mathrm{kg})$ at 114 d gestation & $194(190-199)$ & $190(150-220)$ \\
Change from 90 to 114 d & $28(13-43)$ & $28(15-43)$ \\
Litter size & $11(7-13)$ & $10(8-14)$ \\
Age at insemination & $315(255-598)$ & $276(256-693)$ \\
Piglets & Placebo $(n=52)$ & ICI+RTI $(n=49)$ \\
Delivered alive $(\%)$ & $48(92 \%)$ & $47(96 \%)$ \\
Birth weight* $(\mathrm{g})$ & $1448(720-1990)$ & $1374(560-1884)$ \\
Male sex* $(\%)$ & $29(60 \%)$ & $23(49 \%)$ \\
\hline
\end{tabular}

Mann-Whitney $U$ test, no significant differences. Values are given as median (minimum and maximum).

* Data from alive piglets.

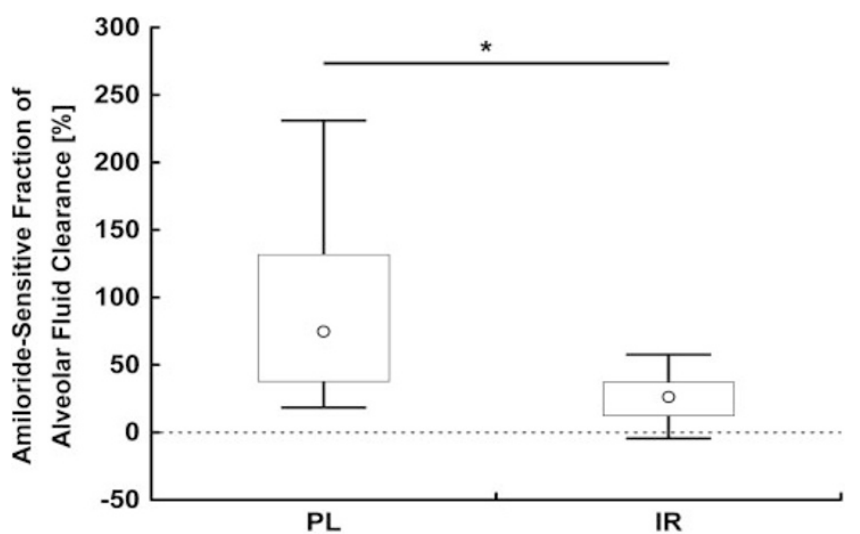

Figure 2. Amiloride-sensitive fraction of alveolar fluid clearance in piglets treated with placebo (PL) or ICI and RTI (IR). Negative numbers indicate fluid secretion. The plot shows median values (horizontal lines) interquartile ranges (boxes) and minimum and maximum values (whiskers). *Statistically significant $(p<0.05$ by Mann-Whitney $U$ test).

Table 2. Lung function parameters

\begin{tabular}{lccc}
\hline & Placebo & ICI+RTI & $p$ \\
\hline Max. AaDO $2(\mathrm{~mm} \mathrm{Hg})$ & $338(151-564)$ & $268(121-443)$ & 0.11 \\
Dyn. compliance $(\mathrm{mL} / \mathrm{mbar} / \mathrm{kg})$ & $0.68(0.39-1.22)$ & $0.63(0.32-1.01)$ & 0.73 \\
Resistance $(\mathrm{mbar} * \mathrm{~s} / \mathrm{mL})$ & $69(49-165)$ & $61(46-329)$ & 0.46 \\
\hline
\end{tabular}

Median (minimum-maximum) values are shown. $p$ Values were calculated with the Mann-Whitney $U$ test.

Table 3. Alveolar counts in different areas of the lung (medians with minimum and maximum, Mann-Whitney $U$ test)

\begin{tabular}{lccc}
\hline & Placebo $(n=15)$ & ICI +RTI $(n=14)$ & $p$ \\
\hline Upper lobe, anterior & $40(26-89)$ & $34(22-69)$ & 0.20 \\
Upper lobe, posterior & $44(33-94)$ & $40(22-68)$ & 0.12 \\
Lower lobe, anterior & $46(28-104)$ & $38(19-69)$ & 0.23 \\
Lower lobe, posterior & $72(33-214)$ & $44(19-118)$ & 0.02 \\
Total & $56(32-113)$ & $38(21-78)$ & 0.03 \\
\hline
\end{tabular}

areas together, piglets of the placebo group had $47 \%$ more alveoli compared with the ICI+RTI group $(p<0.05)$. Alveolar counts were not correlated to birth weight. Figure 3 represents visual fields from the lower posterior lobe from a placebo (Fig. 3A) and an ICI+RTI (Fig. 3B) treated animal. Alveolar diameter and thickness of the interalveolar septa were $58.7 \mu \mathrm{m}(19.7-195)$ and $10.4 \mu \mathrm{m}(6.4-14.6)$ in the placebo group compared with $96.7 \mu \mathrm{m}(39.0-143)$ and 12.1 $\mu \mathrm{m}(7.9-16.8)$ in the ICI+RTI group $(p=0.12$ and 0.06 ,

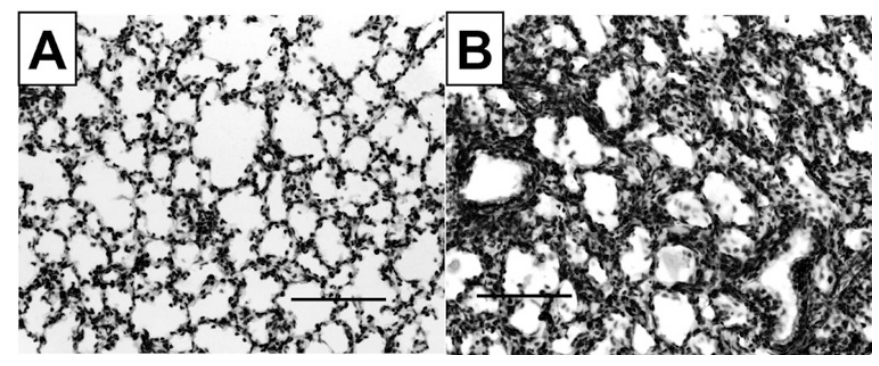

Figure 3. Visual fields from the lower posterior lobe from a placebo- $(A)$ and an ICI+RTI- $(B)$ treated animal. The bar represents $100 \mu \mathrm{m}$ (hematoxylineosin staining). 
respectively). None of the variables of the lung injury score showed a difference between the groups (Table 4).

Plasma levels of ICI in two fetuses aborted 1 wk after the gluteal injection were 2.9 and $2.1 \mathrm{ng} / \mathrm{mL}$ (Analytico Medinet, Breda, Netherlands). One day before term, all samples measured $(n=7)$ showed ICI plasma levels below the lower detection limit of $1 \mathrm{ng} / \mathrm{mL}$.

\section{DISCUSSION}

Amiloride-sensitive AFC was markedly decreased by prenatal application of ICI and RTI at $90 \mathrm{~d}$ of gestation. The persistence of the effect at a time when ICI levels had fallen below the detection limit suggests a reduced expression of channel proteins or a reduced number of alveolar cells due to withdrawal of a stimulatory effect of E2 and P (5).

Values for AFC were lower than those published for adult rabbits (16), and in part negative, indicating persistent fluid secretion. In addition to postnatal lung injury (21), birth by primary cesarean section without labor may have played a part as it prevents the adrenaline-induced activation of alveolar $\mathrm{Na}^{+}$transport (6). Despite the decreased amiloride-sensitive $\mathrm{AFC}$ in piglets treated with ICI+RTI, no difference was found in total AFC, indicating either a concomitant decrease of ion secretory pathways following E2 and $\mathrm{P}$ withdrawal (5) or increased $\mathrm{Na}^{+}$absorption through alternate, amilorideinsensitive channels, such as the cyclic nucleotide gated channel CNG1, which can mediate a considerable proportion of AFC (22).

Similar to ICI+RTI-treated piglets, the AFC and nasal potential of iNOS $(-/-)$ mice lacking the inducible nitric oxide synthase (iNOS) were completely insensitive to the $\mathrm{ENaC}$ blocker amiloride $(23,24)$, in striking contrast to wildtype iNOS $(+/+)$ relatives from the same strain. Alternate amiloride-insensitive pathways, largely unknown to date, may be involved in pulmonary epithelial vectorial $\mathrm{Na}^{+}$transport of iNOS (-/-) mice. Endogenous NO production by iNOS may up-regulate $\mathrm{ENaC}$ and amiloride-sensitive $\mathrm{AFC}$ and downregulate the alternate pathways, in contrast to acute pharmacologic interventions, such as application of a chemical NO donor (16) or blockade of iNOS with S-methylthiourea (24). These observations gain further relevance by the fact that estrogens are capable of increasing iNOS expression up to 27 -fold, which can be prevented by ICI (25). It is possible that

Table 4. Lung injury scores (0-4 points for the single variables and up to 36 points for the total score) of the lung from piglets of the control and the treated group (Mann-Whitney U test)

\begin{tabular}{lccc}
\hline & Placebo $(n=15)$ & ICI+RTI $(n=14)$ & $p$ \\
\hline Inflammation, alveolar & $0.20(0-1.25)$ & $0.25(0-0.75)$ & 0.23 \\
Inflammation, interstitial & $2.30(1.00-3.50)$ & $2.30(1.5-3.0)$ & 0.88 \\
Hemorrhage, alveolar & $0.25(0-1.00)$ & $0.27(0-0.75)$ & 0.40 \\
Hemorrhage, interstitial & $0.83(0-1.50)$ & $0.96(0.50-1.50)$ & 0.59 \\
Edema, alveolar & 0 & 0 & - \\
Edema, interstitial & $1.77(0-3.50)$ & $1.50(0-2.75)$ & 0.45 \\
Atelectasis & $0.98(0-2.25)$ & $0.70(0.25-2.25)$ & 0.33 \\
Overinflation & $2.25(1.50-3.00)$ & $2.53(1.75-3.00)$ & 0.15 \\
Necrosis & 0 & 0 & - \\
Total & $10.5(6.5-15.3)$ & $11.4(7.5-14.0)$ & 0.89 \\
\hline
\end{tabular}

the effects of estrogen-receptor blockade on AFC are mediated, at least in part, through alterations of iNOS expression. Decreased iNOS expression may have also resulted in fewer intrapulmonary shunts and may thus be a possible explanation for the unexpected trend toward a lower $\mathrm{AaDO}_{2}$ in ICI+RTItreated piglets. Fewer alveoli with thicker walls would usually result in decreased oxygen uptake and, therefore, in a higher $\mathrm{AaDO}_{2}$ in ICI+RTI-treated piglets. However, such trends may occur by chance, and must therefore be interpreted with great caution.

In human subjects, female sex was associated with higher AFC and lower morbidity and mortality in adults with acute respiratory distress syndrome (26) as well as a lower incidence of respiratory distress syndrome in numerous studies of premature infants (27). More than $30 \mathrm{y}$ ago, a single intramuscular injection of aqueous estrogens immediately after birth reduced the incidence of respiratory distress syndrome in premature infants in a randomized trial (10), possibly by improving their AFC (7) or surfactant production $(9,28)$. Conversely, in cystic fibrosis, in which hyperactivity of $\mathrm{Na}^{+}$ absorption contributes to pathologic thickening of mucus (29), male sex is associated with a better prognosis (30), possibly because female sex hormones worsen (increase) the hyperactivity of $\mathrm{Na}^{+}$absorption.

Alveolarization begins to start at about $90 \mathrm{~d}$ of gestation in the pig fetus (15). ICI and RTI applied at this gestational age resulted in significantly impaired alveolarization, preserving a histologic picture previously known from 92-d pig fetuses (15). The constitutively slower development of the lower lobe may explain why ICI and RTI more profoundly affected the lower posterior lobe. These results are consistent with increased alveolarization in the offspring of E2-treated pregnant rabbits (9), increased alveolar formation in female rats (8) and impaired alveolarization in female mice lacking the estrogen receptor beta (31). E2 and P may affect alveolar formation by modifying vascular endothelial growth factor (VEGF) expression (32,33), which is supported by significantly reduced aerated lung and increased alveolar septal thickness found in VEGF (-/-) mice (34). However, it remains to be shown that pulmonary VEGF is under regulation of E2 and $\mathrm{P}$. The decreased number of alveoli may also explain the difference in amiloride-sensitive AFC because even if AFC remains constant at the cellular level, total transport will be reduced if there are fewer cells. As the alveolar counts were most strongly reduced in the lower lobe, where the AFC was measured, the results of AFC measurements may not be representative for other parts of the lung.

The interlitter variabilities of AFC measurements and alveolar counts were indistinguishable from the intralitter variabilities, which may be explained by breeding practices resulting in a very low genetic variability. Therefore, piglets (or piglet pairs in case of amiloride sensitive AFC measurements) were treated as independent observations.

In bronchopulmonary dysplasia (BPD), histopathological studies demonstrated an arrest of lung development with reduced number of alveoli, similar to observations presented in this study (35). This so-called new BPD (36) may be secondary to a postnatal lack of factors that normally regulate 
prenatal lung differentiation and maturation, resulting in arrested lung development. The human fetus is normally exposed to increasing amounts of both $\mathrm{E} 2$ and $\mathrm{P}$ with advancing gestational age derived from the fetoplacentomaternal unit (37). Within $1 \mathrm{~d}$ of birth, the levels of E2 and P drop 100-fold (38). Preterm infants are deprived of the placental E2 and P supply at a much earlier developmental stage than term infants. Postnatal replacement of E2 and P to maintain levels expected in utero was associated with a trend toward a lower incidence of BPD (38).

It is noteworthy that despite undetectable plasma levels of ICI at delivery, effects on alveolarization and AFC persisted until term birth, supporting the concept of distinct developmental time windows in which a temporary deprivation of essential factors may have persistent effects on differentiation and function (39). Unfortunately, no methods were available to determine the plasma levels of RTI. Cross-reactivity of RTI at the glucocorticoid receptors is unlikely (13) but cannot be excluded. This study cannot separate the effects of E2 or P antagonism because only the combination was tested. Further studies must also account for the dose-response relationships of the antagonists used and consider the network of other mediators involved in differentiation and function during lung development.

Acknowledgments. The authors thank C. E. Cook for providing RTI 3021-022, P. E. Heyde for providing guajazulen, Heinen Löwenstein and Dräger companies for providing neonatal ICU equipment, V.G. Nielsen for invaluable advice in measuring AFC, and the staff of the Clinic for Veterinary Gynecology and Obstetrics, University Munich, Germany, for their excellent assistance in performing the animal studies.

\section{REFERENCES}

1. Couse JF, Korach KS 1998 Exploring the role of sex steroids through studies of receptor deficient mice. J Mol Med 76:497-511

2. Beyer C 1999 Estrogen and the developing mammalian brain. Anat Embryol 199:379-390

3. Beyer C, Küppers E, Karolczak M, Trotter A 2003 Ontogenetic expression of estrogen and progesterone receptors in the mouse lung. Biol Neonate 84:59-63

4. Hummler E, Barker P, Gatzy J, Beermann F, Verdumo C, Schmidt A, Boucher R, Rossier BC 1996 Early death due to defective neonatal lung liquid clearance in $\alpha E N a C$-deficient mice. Nat Genet 12:325-328

5. Sweezey N, Tchepichev S, Gagnon S, Fertuck K, O’Brodovich H 1998 Female gender hormones regulate mRNA levels and function of the rat lung epithelial $\mathrm{Na}$ channel. Am J Physiol 274:C379-C386

6. Gowen CW, Lawson EE, Gingras J, Boucher RC, Gatzy JT, Knowles MR 1988 Electrical potential difference and ion transport across nasal epithelium of term neonates: correlation with mode of delivery, transient tachypnea of the newborn, and respiratory rate. J Pediatr 113:121-127

7. Barker PM, Gowen CW, Lawson EE, Knowles MR 1997 Decreased sodium ion absorption across nasal epithelium of very premature infants with respiratory distress syndrome. J Pediatr 130:373-377

8. Massaro GD, Mortola JP, Massaro D 1996 Estrogen modulates the dimensions of the lung's gas-exchange surface area and alveoli in female rats. Am J Physiol 270:L110 L114

9. Khosla SS, Smith GJ, Parks PA, Rooney SA 1981 Effects of estrogen on fetal rabbit lung maturation: morphological and biochemical studies. Pediatr Res 15:1274-1281

10. Shanklin DR, Wolfson SL 1970 Aqueous estrogens in the management of respiratory distress syndrome. J Reprod Med 5:53-71

11. Wakeling AE, Bowler J 1992 ICI 182,780, a new antioestrogen with clinical potential. J Steroid Biochem Mol Biol 43:173-177
12. Wijayaratne AL, Nagel SC, Paige LA, Christensen DJ, Norris JD, Fowlkes DM, McDonnell DP 1999 Comparative analyses of mechanistic differences among antiestrogens. Endocrinology 140:5828-5840

13. Wagner BL, Pollio G, Giangrande P, Webster JC, Breslin M, Mais DE, Cook CE, Vedeckis WV, Cidlowski JA, McDonnell DP 1999 The novel progesterone receptor antagonists RTI 3021-012 and RTI 3021-022 exhibit complex glucocorticoid receptor antagonist activities: implications for the development of dissociated antiprogestins. Endocrinology 140:1449-1458

14. Ash RW, Heap RB 1975 Oestrogen, progesterone and corticosteroid concentrations in peripheral plasma of sows during pregnancy, parturition, lactation and after weaning. J Endocrinol 64:141-154

15. Baskerville A 1976 Histological and ultrastructural observations on the development of the lung of the fetal pig. Acta Anat 95:218-233

16. Nielsen VG, Baird MS, Chen L, Matalon S 2000 DETANONOate, a nitric oxide donor, decreases amiloride-sensitive alveolar fluid clearance in rabbits. Am J Respir Crit Care Med 161:1154-1160

17. Ponzilius KH, Parvizi N, Elaesser F, Ellendorff F 1986 Ontogeny of secretory patterns of LH release and effects of gonadectomy in the chronically catheterized pig fetus and neonate. Biol Reprod 34:602-612

18. Thome UH, Schulze A, Schnabel R, Franz AR, Pohlandt F, Hummler HD 2001 Partial liquid ventilation in severely surfactant-depleted, spontaneously breathing rabbits supported by proportional assist ventilation. Crit Care Med 29:1175-80

19. Gortner L, Hilgendorff A, Bähner T, Ebsen M, Reiss I, Rudloff S 2005 Hypoxiainduced intrauterine growth retardation: effects on pulmonary development and surfactant protein transcription. Biol Neonate 88:129-135

20. Smith KM, Mrozek JD, Simonton SC, Bing DR, Meyers PA, Connett JE, Mammel MC 1997 Prolonged partial liquid ventilation using conventional and high- frequency ventilatory techniques: gas exchange and lung pathology in an animal model of respiratory distress syndrome. Crit Care Med 25:1888-1897

21. Lecuona E, Saldias F, Comellas A, Ridge K, Guerrero C, Sznajder JI 1999 Ventilator-associated lung injury decreases lung ability to clear edema in rats. Am J Respir Crit Care Med 159:603-609

22. Junor RW, Benjamin AR, Alexandrou D, Guggino SE, Walters DV 1999 A novel role for cyclic nucleotide-gated cation channels in lung liquid homeostasis in sheep. J Physiol 520:255-260

23. Hardiman KM, Lindsey JR, Matalon S 2001 Lack of amiloride-sensitive transport across alveolar and respiratory epithelium of iNOS(-/-) mice in vivo. Am J Physiol Lung Cell Mol Physiol 281:L722-L731

24. Elmer HL, Brady KG, Drumm ML, Kelley TJ 1999 Nitric oxide-mediated regulation of transepithelial sodium and chloride transport in murine nasal epithelium. Am J Physiol 276:L466-L473

25. Mershon JL, Baker RS, Clark KE 2002 Estrogen increases iNOS expression in the ovine coronary artery. Am J Physiol Heart Circ Physiol 283:H1169-H1180

26. Ware LB, Matthay MA 2001 Alveolar fluid clearance is impaired in the majority of patients with acute lung injury and the acute respiratory distress syndrome. Am J Respir Crit Care Med 163:1376-1383

27. Hallman M, Haataja R 2003 Genetic influences and neonatal lung disease. Semin Neonatol 8:19-27

28. Thuresson-Klein A, Moawad AH, Hedqvist P 1985 Estrogen stimulates formation of lamellar bodies and release of surfactant in the rat fetal lung. Am J Obstet Gynecol 151:506-514

29. Jiang C, Finkbeiner WE, Widdicombe JH, McCray PB, Miller SS 1993 Altered fluid transport across airway epithelium in cystic fibrosis. Science 262:424-427

30. Corey M, Farewell V 1996 Determinants of mortality from cystic fibrosis in Canada, 1970-1989. Am J Epidemiol 143:1007-1017

31. Massaro D, Massaro GD 2004 Estrogen regulates pulmonary alveolar formation, loss, and regeneration in mice. Am J Physiol Lung Cell Mol Physiol 287:L1154 L1159

32. Jesmin S, Sakuma I, Hattori Y, Kitabatake A 2002 In vivo estrogen manipulations on coronary capillary network and angiogenic molecule expression in middle-aged female rats. Arterioscler Thromb Vasc Biol 22:1591-1597

33. Sengupta K, Banerjee S, Saxena N, Banerjee SK 2003 Estradiol-induced vascular endothelial growth factor-A expression in breast tumor cells is biphasic and regulated by estrogen receptor-alpha dependent pathway. Int J Oncol 22:609-614

34. Compernolle V, Brusselmans K, Acker T, Hoet P, Tjwa M, Beck H, Plaisance S, Dor Y, Keshet E, Lupu F, Nemery B, Dewerchin M, Van Veldhoven P, Plate K, Moons L, Collen D, Carmeliet P 2002 Loss of HIF-2alpha and inhibition of VEGF impair fetal lung maturation, whereas treatment with VEGF prevents fatal respiratory distress in premature mice. Nat Med 8:702-710

35. Husain AN, Siddiqui NH, Stocker JT 1998 Pathology of arrested acinar development in postsurfactant bronchopulmonary dysplasia. Hum Pathol 29:710-717

36. Jobe AJ 1999 The new BPD: an arrest of lung development. Pediatr Res 46:641-643

37. Tulchinsky D, Hobel CJ, Yeager E, Marshall JR 1972 Plasma estrone, estradiol, estriol, progesterone, and 17-hydroxyprogesterone in human pregnancy. I. Normal pregnancy. Am J Obstet Gynecol 112:1095-1100

38. Trotter A, Maier L, Grill HJ, Kohn T, Heckmann M, Pohlandt F 1999 Effects of postnatal estradiol and progesterone replacement in extremely preterm infants. J Clin Endocrinol Metab 84:4531-4535

39. Cooke B, Hegstrom CD, Villeneuve LS, Breedlove SM 1998 Sexual differentiation of the vertebrate brain: principles and mechanisms. Front Neuroendocrinol 19:323362 